\title{
Incidência e fatores causais das supressões da arborização urbana no município de Itapira, Estado de São Paulo
}

\author{
Incidence and causing factors of urban tree cutting in \\ the city of Itapira, State of São Paulo, Brazil
}

Anderson Martelli[a], Joaquim Barbosa Junior ${ }^{[b]}$

[a] Biólogo, especialista em Laboratório Clínico da Prefeitura Municipal de Itapira, Secretaria de Agricultura e Meio Ambiente, Itapira, São Paulo - Brasil, e-mail: martelli@fcm.unicamp.br

[b] Administrador e secretário da Prefeitura Municipal de Itapira, Secretaria de Agricultura e Meio Ambiente, Itapira, São Paulo - Brasil, e-mail: joaquim.barbosa@itapira.sp.gov.br

\section{Resumo}

Por falta de planejamento, o plantio de árvores em vias públicas tem gerado problemas aos moradores, aumentado os pedidos de supressão dessas árvores. Este trabalho objetivou realizar uma análise quantitativa das causas que determinaram essa supressão e as regiões de maior incidência desses cortes, no período de janeiro a outubro de 2010, dentro do perímetro urbano do município de Itapira, SP. Para isso realizou-se um levantamento de dados na Secretaria de Agricultura e Meio Ambiente (Sama) do referido município, responsável pelas autorizações de corte. Os resultados demonstraram que foram suprimidas 111 árvores, sendo o bairro Prados o que apresentou o maior número de árvores cortadas (12). Na análise quantitativa das espécies suprimidas, a Ficus benjamina e a Ligustrum lucidum foram as mais suprimidas, correspondendo a quase $40 \%$ do total de supressões. Noventa e uma árvores foram suprimidas por causas isoladas, sendo as rachaduras nas calçadas o principal motivo desses cortes (19 árvores; 20,9\%). Nas supressões que ocorreram por dois motivos ou mais, 20 árvores foram suprimidas, sendo o ataque por brocas e tronco apodrecido responsável por $50 \%$ das supressões (10 árvores).

Palavras-chave: Arborização. Vegetação urbana. Rachaduras na calçada. Itapira.

\section{Abstract}

The lack of urban planning for the planting of trees on public streets has caused problems for the citizens and lead to the increase in the requests for tree removal. This research aimed to quantitatively analyze the causes for removal of urban trees in the city of Itapira, São Paulo, Brazil as well as to identify the neighborhoods with highest incidence of cuts in the period ranging from January to October 2010. Data were obtained from the city's Department of Agriculture and Environment (Sama), which is responsible for issuing cutting authorizations. Results showed that a total of 111 trees were cut and the neighborhood of Prados had the most trees 
removed (12). Ficus benjamina and Ligustrum lucidum were the most commonly cut species (22 trees of each species; $40 \%$ of total). Nineteen out of the 91 trees cut for isolated reasons were eliminated for causing sidewalk damage. Out of 20 trees that were removed for two or more combined reasons, 50\% were cut because of the combination of stem borer infestation and decaying trunks.

Keywords: City trees. Urban vegetation. Sidewalk damage. Itapira.

\section{Introdução}

A árvore é a forma vegetal mais característica na paisagem urbana, à qual, ao longo da história, tem se incorporado em estreita relação à arquitetura das cidades. A arborização urbana contribui para a obtenção de um ambiente urbano agradável e tem influência decisiva na qualidade de vida nas cidades e, portanto, na saúde da população. A importância da árvore, no meio urbano, ganha relevância maior, principalmente quando a concentração das habitações aumenta (MÜLLER, 1998).

A arborização urbana em vias públicas é fundamental para a manutenção da qualidade de vida, proporcionando conforto aos habitantes das cidades, pois contribui com a estabilização climática, embeleza, fornece abrigo e alimento à fauna e sombra e lazer às ruas e avenidas das cidades (COLETTO et al., 2008; GRAZIANO, 1994; RODOLFO JUNIOR et al., 2008; SILVA FILHO et al., 2002).

Os estudos de Alves e Gouveia (1995) destacaram que as propriedades que ficavam próximas às áreas arborizadas eram mais valorizadas, apresentavam um baixo índice de mudança de residência e que as folhagens eram tema dominante na memória das crianças que moravam na cidade. Isso foi explicado pelos benefícios propiciados pelas árvores, como aumento da diversidade sensorial, diminuição do vandalismo, redução do consumo de energia e a satisfação dos moradores com as residências.

A arborização urbana no Brasil é de competência das administrações municipais. Embora haja uma crescente disposição, tanto dos órgãos governamentais envolvidos como de grande parcela da população, muitos são os problemas enfrentados, como a falta de técnicos capacitados que orientem plantios corretos, a escolha das espécies, podas de formação, utilização de tutores, grades de proteção, irrigações em período de estiagem e adubações (RIBEIRO, 2009).
Segundo Bortoleto et al. (2006), muitas cidades brasileiras não possuem um planejamento adequado de arborização urbana e a maioria dos projetos baseiam-se em métodos puramente empíricos, desprovidos de um conhecimento real do assunto.

Desse modo, para alcançar a qualidade do ambiente urbano, é necessário realizar um planejamento prévio. Contudo, quando não há planejamento dessa arborização, inúmeros problemas podem ocorrer e, em vez de um elemento benéfico, a arborização passa a representar um foco de conflito nas cidades (COLETTO et al., 2008).

De acordo com Teixeira (1999) e Rodrigues (2002), as cidades são todas iguais, possuindo inúmeras características em comum, como sistema viário (estruturado ou não), espaços residenciais, espaços comerciais e de serviço, espaços industriais, espaços institucionais e espaços livres ou abertos. $\mathrm{E}$ a julgar tanto pela forma universalizante do tratamento das questões urbanas quanto pelas normas gerais que regem a urbanização no Brasil, a começar pelos códigos de postura municipais e leis de loteamentos, é de se considerar que as cidades, em todos os lugares, sejam mesmo muito parecidas.

Dessa forma, planejar a arborização é indispensável para o desenvolvimento urbano e requer, antes de qualquer coisa, o conhecimento da situação existente, o que pode ser conseguido por meio de um inventário qualiquantitativo, assim como o conhecimento das características dos vegetais que poderão ser utilizados (COLETTO et al., 2008).

Atualmente, a gestão da arborização urbana no município de Itapira, SP, é de responsabilidade da Secretaria de Agricultura e Meio Ambiente (Sama), órgão vinculado à Prefeitura Municipal, que por meio da vistoria de seus técnicos dá parecer favorável ou não à supressão da arborização urbana do município.

0 objetivo deste trabalho foi realizar um estudo transversal, com o levantamento de dados nos arquivos do referido órgão, quanto às espécies e ao 
número de indivíduos suprimidos, quanto aos motivos que levaram a essas supressões e quanto aos bairros de maior incidência de supressões no município de Itapira, SP, no período de janeiro a outubro de 2010.

Levando em consideração a importância da arborização urbana para o bem estar da população e a grande escassez de informações sobre os motivos que levam os moradores de uma cidade a solicitar, de forma exacerbada, supressões de árvores nos espaços urbanos, este trabalho tem o objetivo de levantar as principais causas de supressão da arborização urbana de Itapira. Tais informações vêm subsidiar o planejamento que valorize o aspecto paisagístico ecológico com a utilização de espécies adequadas e compatíveis com as características físicas da cidade.

\section{Materiais e métodos}

\section{Caracterização do município de Itapira}

0 município de Itapira integra a Região Administrativa de Campinas e está localizado na região Sudeste, porção centro-leste, do Estado de São Paulo, a $22^{\circ} 26^{\prime} 10^{\prime \prime}$ de latitude S e $46^{\circ} 49^{\prime} 18^{\prime \prime}$ de longitude W, distando aproximadamente $63 \mathrm{~km}$ (via anel de contorno) da cidade de Campinas e 159 km da capital do Estado.

Itapira possui uma área de $518,385 \mathrm{~km}^{2}$, com uma estimativa populacional de 71.850 habitantes. 0 perímetro urbano, alvo do estudo, apresenta uma área de $58.042 \mathrm{~m}^{2}$ (Figura 1) com uma densidade demográfica de 132,2 habitantes por $\mathrm{km}^{2}$ (IBGE, 2009). Segundo dados do setor de Lançadoria da Prefeitura, essa área conta hoje com 20.600 imóveis.

As primeiras indústrias do município estiveram relacionadas à ferrovia e à agricultura local e regional, por meio de fábricas de implementos agrícolas. Atualmente, a atividade industrial de Itapira é representada por indústrias de embalagens de papelão, brinquedos, mecânica, máquinas e implementos agrícolas, transformação de madeira e marcante presença de usina de açúcar e álcool e atividades extrativistas (mineração).

O saneamento básico de Itapira é um dos maiores referenciais do município. Hoje, 100\% dos imóveis urbanos recebem água tratada e têm seu esgoto
$100 \%$ coletado e tratado, com eficiência de $82 \%$ após passar pelo sistema de lagoas.

Itapira encontra-se incluída na "Serrania de Lindóia”, segundo subdivisão geomorfológica do Estado de São Paulo, proposta no Mapa Geomorfológico do Estado de São Paulo (IPT, 2007).

O clima predominante na região é o tropical de altitude (CWA), conforme a classificação de Köppen, caracterizado por mais de 60 dias secos, temperatura máxima anual de $29^{\circ} \mathrm{C}$, temperatura mínima anual de $5{ }^{\circ} \mathrm{C}$ e precipitação média anual em torno de $1.600 \mathrm{~mm}$ (SETZER, 1976).

\section{Levantamento quantitativo}

Os processos de supressão arbórea no município de Itapira, SP, iniciam-se com uma vistoria realizada por técnicos da Sama, em que, após criteriosa inspeção, é preenchido um laudo de "Solicitação de Corte de Árvore", informando as condições fitossanitárias e biomecânicas e/ou relatando o motivo da supressão do indivíduo, caso seja deferido seu corte por técnico.

A partir desses procedimentos foi realizada uma análise exploratória de dados nos arquivos da Sama de Itapira, SP, quanto às solicitações de corte de

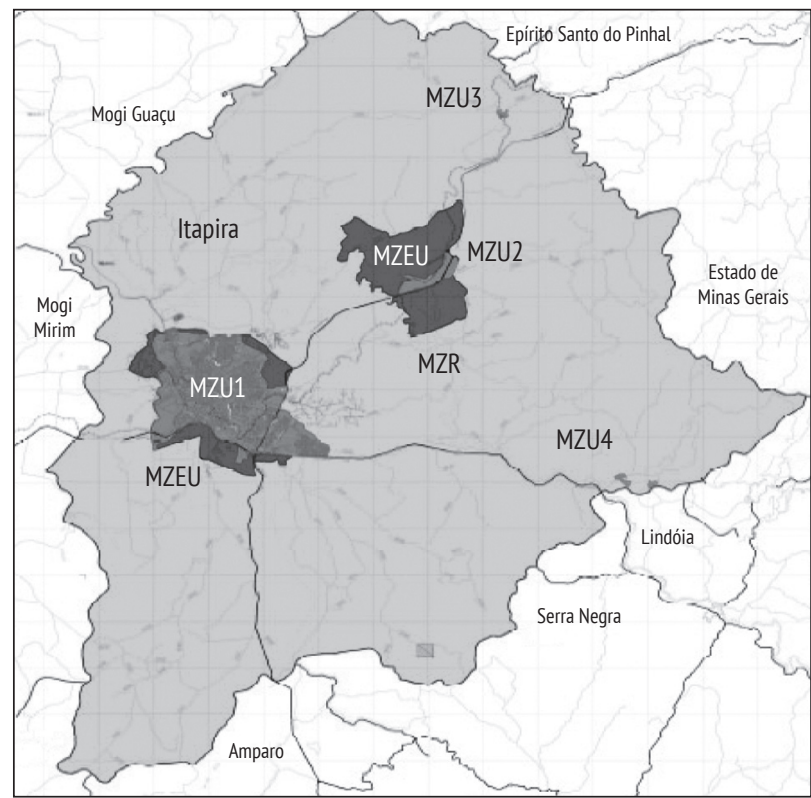

Figura 1 - Macrozoneamento urbano do município de Itapira, SP (MZU1 - área urbana)

Fonte: Adaptado do Plano Diretor do Município de Itapira, 2006. 
árvores deferidas dentro do perímetro urbano do município, no período de janeiro a outubro de 2010.

Os dados analisados no levantamento foram: espécies e número de indivíduos suprimidos por espécie, localização das árvores suprimidas no município (número de indivíduos/bairro), nome científico e os motivos que levaram à supressão dessas árvores.

\section{Resultados e discussão}

Segundo os dados levantados no período de janeiro a outubro de 2010, foram autorizados pelos técnicos da Sama a supressão de 111 exemplares arbóreos distribuídos em 32 bairros do município de Itapira, SP (Tabela 1).

Da análise do número de árvores suprimidas em relação à sua localização (bairro), foi possível observar que o bairro Prados apresentou a maior incidência de árvores cortadas, com 10,8\% do total (12 indivíduos), seguido pelo bairro Figueiredo com 7,2\% (8 indivíduos) (Tabela 1).

$\mathrm{Na}$ análise quantitativa das espécies suprimidas, do total de 111 árvores distribuídas em 15 famílias, o Ficus benjamina (Moraceae) e Ligustrum lucidum (Oleaceae) foram as espécies mais suprimidas, com 22 indivíduos/espécie, correspondendo a 19,8\% dos cortes cada uma. Em seguida ficou a espécie Caesalpinia peltphoroides (Leguminoseae-Caesalpinioideae), com 18 indivíduos suprimidos, correspondendo a $16,2 \%$ do total (Tabela 2).

Os dados obtidos neste estudo corroboram os dados de Santana e Santos (1999), os quais relataram que o Ficus benjamina é uma das espécies mais prejudiciais ao calçamento e à estrutura viária da cidade, e o gênero Ficus é causador de grandes problemas como elemento de arborização no Câmpus da Universidade Estadual de Feira de Santana (UEFS), por danificar calçadas.

Rossetti et al. (2010) e Almeida e Barbosa (2010) ressaltaram que diversos gêneros de Ficus mostraram ser de porte desfavorável ao plantio em calçadas, tendo contato direto com a rede elétrica, pondo em risco a vida humana durante a poda ou descarga elétrica durante chuvas e obstruindo a visão dos condutores de veículos.

Gonçalves e Rocha (2010) mostraram também um número significativo de indivíduos arbóreos com sistema radicular superficial causando danos ao cal-
Tabela 1 - Distribuição das árvores suprimidas nos bairros do município de Itapira, SP, no período de janeiro a outubro de 2010

\begin{tabular}{|c|c|c|}
\hline Bairro & $\begin{array}{l}\text { N. de árvores } \\
\text { suprimidas }\end{array}$ & $\begin{array}{c}\text { Frequência } \\
\text { (\%) }\end{array}$ \\
\hline Prados & 12 & 10,8 \\
\hline Santa Cruz & 7 & 6,3 \\
\hline São Benedito & 1 & 0,9 \\
\hline Jardim Soares & 2 & 1,8 \\
\hline Della Rocha 1 & 4 & 3,6 \\
\hline Della Rocha 2 & 3 & 2,7 \\
\hline Istor Luppi & 1 & 0,9 \\
\hline São Vicente & 5 & 4,5 \\
\hline Assad Alcici & 1 & 0,9 \\
\hline Centro & 7 & 6,3 \\
\hline Braz Cavenaghi & 3 & 2,7 \\
\hline Vila Izaura & 3 & 2,7 \\
\hline Figueiredo & 8 & 7,2 \\
\hline Nosso Teto & 4 & 3,6 \\
\hline Boa Esperança & 2 & 1,8 \\
\hline Nova Itapira & 3 & 2,7 \\
\hline Jardim Magali & 2 & 1,8 \\
\hline Pé no Chão & 2 & 1,8 \\
\hline Flavio Zacchi & 3 & 2,7 \\
\hline Penha do Rio do Peixe & 5 & 4,5 \\
\hline Santa Marta & 5 & 4,5 \\
\hline Vila Ilze & 2 & 1,8 \\
\hline Vila Pereira & 2 & 1,8 \\
\hline Jardim Guarujá & 1 & 0,9 \\
\hline Bela Vista & 1 & 0,9 \\
\hline Jardim Itamaracá & 2 & 1,8 \\
\hline Jardim Boa Vista & 2 & 1,8 \\
\hline Aquiles Galdi & 3 & 2,7 \\
\hline Cubatão & 5 & 4,5 \\
\hline Jardim Raquel & 2 & 1,8 \\
\hline Humberto Carlos Passarella & 3 & 2,7 \\
\hline São Lucas & 5 & 4,5 \\
\hline Total & 111 & $100 \%$ \\
\hline
\end{tabular}

Fonte: Dados da pesquisa.

çamento. Dentre estes, o Ligustrum lucidum (alfeneiro) destacou-se, uma vez que essa espécie foi abundantemente plantada no bairro há muitos anos e, consequentemente, apresentou os indivíduos de maior porte. 
Tabela 2 - Listagem das espécies referidas como úteis pelos especialistas locais moradores no entorno da Reserva Biológica do Tinguá (ERBT), Nova Iguaçu, RJ

\begin{tabular}{|c|c|c|c|c|}
\hline Família e espécie & Nome popular & Origem* & N. de indivíduos & Freq. (\%) \\
\hline \multicolumn{5}{|l|}{ Bignoniaceae } \\
\hline Tecoma stans & Ipê-Mirim & $\mathrm{E}$ & 1 & 0,9 \\
\hline Spathodea campanulata & Espatódea & $\mathrm{E}$ & 2 & 1,8 \\
\hline Tabebuia roseo-alba & Ipê-Branco & $\mathrm{N}$ & 1 & 0,9 \\
\hline \multicolumn{5}{|l|}{ Apocynaceae } \\
\hline Nerium oleander & Espirradeira & $\mathrm{E}$ & 1 & 0,9 \\
\hline \multicolumn{5}{|l|}{ Moraceae } \\
\hline Ficus benjamina & Ficus & $\mathrm{E}$ & 22 & 19,8 \\
\hline \multicolumn{5}{|l|}{ Oleaceae } \\
\hline Ligustrum lucidum & Alfeneiro & $\mathrm{E}$ & 22 & 19,8 \\
\hline \multicolumn{5}{|l|}{ Proteaceae } \\
\hline Grevillea banksii & Grevilea anã & E & 1 & 0,9 \\
\hline \multicolumn{5}{|l|}{ Leguminoseae } \\
\hline Caesalpinia peltphoroides & Sibipiruna & $\mathrm{N}$ & 18 & 16,2 \\
\hline Bauhinia longifolia & Pata-de-vaca & $\mathrm{E}$ & 4 & 3,6 \\
\hline Leucaena leucoce & Leucena & $\mathrm{E}$ & 3 & 2,7 \\
\hline Cassia fistula & Cássia-imperial & $\mathrm{E}$ & 1 & 0,9 \\
\hline- & Não identificada & - & 9 & 8,1 \\
\hline \multicolumn{5}{|l|}{ Palmaceae } \\
\hline Roystonea oleracea & Palmeira-imperial & E & 1 & 0,9 \\
\hline \multicolumn{5}{|l|}{ Lythraceae } \\
\hline Lagerstroemia indica & Resedá & E & 1 & 0,9 \\
\hline \multicolumn{5}{|l|}{ Punicaceae } \\
\hline Punica granatum & Romã & E & 2 & 1,8 \\
\hline \multicolumn{5}{|l|}{ Rutaceae } \\
\hline Murraya exótica & Murta & $\mathrm{E}$ & 3 & 2,7 \\
\hline \multicolumn{5}{|l|}{ Anacardiaceae } \\
\hline Shinus mole & Aroeira salsa & $\mathrm{N}$ & 9 & 8,1 \\
\hline Maganifera indica & Mangueira & $\mathrm{E}$ & 3 & 2,7 \\
\hline \multicolumn{5}{|l|}{ Pinaceae } \\
\hline Pinus elliottii & Pinus & E & 1 & 0,9 \\
\hline \multicolumn{5}{|l|}{ Lauraceae } \\
\hline Nectandra megapotamica & Canelinha & $\mathrm{N}$ & 1 & 0,9 \\
\hline \multicolumn{5}{|l|}{ Combretaceae } \\
\hline Terminalia catappa & Chapéu de sol & E & 4 & 3,6 \\
\hline \multicolumn{5}{|l|}{ Polygonaceae } \\
\hline Triplaris brasiliana & Pau-formiga & $\mathrm{N}$ & 1 & 0,9 \\
\hline Total & & & 111 & $100 \%$ \\
\hline
\end{tabular}

Legenda: ${ }^{*} \mathrm{E}=$ exótica; $\mathrm{N}=$ nativa.

Fonte: Dados da pesquisa. 
Esses problemas são muito comumente observados e causam, na maioria das vezes, um manejo inadequado e prejudicial às árvores, como podas drásticas, as quais comprometem sua estrutura e podem levar à sua supressão.

Neste estudo foram identificados diversos motivos que levaram à supressão de árvores. Esses motivos foram agrupados em dois grupos, conforme descrição a seguir:

- Motivos isolados: espaço insuficiente; apodrecimento do tronco; rachaduras nas calçadas; ataque por cupim; risco de queda; entupimento da rede de esgoto; árvore morta; construção e reformas de casas, muros ou mudanças na arquitetura da residência; ataque por broca; e espécie imprópria para calçada.

- Motivos associados: ataque por cupim e tronco apodrecido; apodrecimento e risco de queda; ataque por broca e cupim; rachadura na calçada e tronco apodrecido; ataque por broca e rachadura na calçada; rachadura na calçada e entupimento da rede de esgoto; e ataque por broca e tronco apodrecido.

Um total de 111 indivíduos arbóreos foi suprimido em Itapira no período mencionado. Desse total, 91 indivíduos foram suprimidos por motivos isolados e 20 por motivos associados. Os principais motivos isolados foram as rachaduras nas calçadas (19 indivíduos; 20,9\%), as construções e reformas de casas, muros ou mudanças na arquitetura da residência (17 indivíduos; 18,7\%) e o apodrecimento do tronco (15 indivíduos; 16,5\%). Esses motivos representaram, juntos, mais da metade dos cortes deferidos (56\%) (Figura 2).

0 restante das supressões (44\%) se deu em razão dos motivos associados, sendo o ataque por brocas e tronco apodrecido o maior deles (10 indivíduos; $50 \%$ ), seguido por ataque por cupins e tronco apodrecido (4 indivíduos; $20 \%$ ) e rachaduras nas calçadas e entupimento da rede de esgoto ( 2 indivíduos; 10\%) (Figura 3).

0 número de árvores suprimidas por serem impróprias para as calçadas foi bastante significativo neste estudo (13 indivíduos). De acordo com Ribeiro (2009), o plantio de árvores inadequadas à estrutura urbana gera conflitos com equipamentos urbanos como fiações elétricas, encanamentos, calhas, calça-

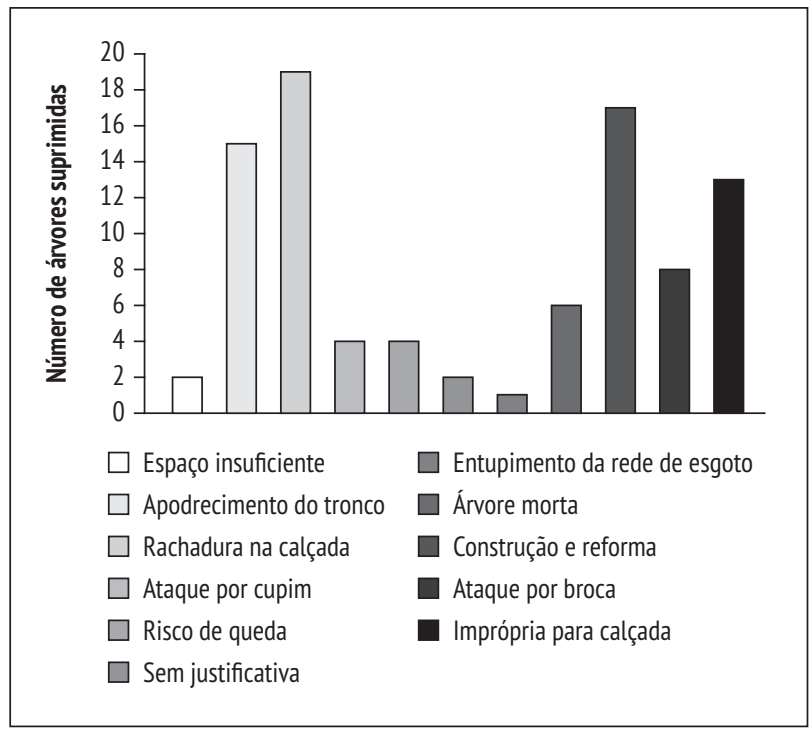

Figura 2 - Motivos isolados de supressão de árvores no Município de Itapira, SP, no período de janeiro a outubro de 2010

Fonte: Dados da pesquisa.

mentos, muros, postes de iluminação e outros. Entretanto, segundo Rossetti et al. (2010), as espécies adequadas para serem usadas nas calçadas ainda são muito pouco estudadas no Brasil.

No estudo realizado por Faleiro e Amâncio-Pereira (2007) sobre arborização viária, realizada no câmpus Umuarama da Universidade Federal de Uberlândia, MG, foi observado que $54,3 \%$ das árvores plantadas apresentaram conflitos com o calçamento em razão do porte desproporcional ou espaço da base do tronco insuficiente.

Ribeiro (2009) afirma que a maioria dos danos causados nas calçadas muitas vezes ocorre por causa de um plantio inadequado, em que é deixado um espaçamento pequeno para o crescimento do caule vegetal, e/ou por falta de orientação dos moradores, esquecendo-se que a muda depois de plantada vai crescer com um aumento considerável do raio do caule interferindo no calçamento.

Segundo Silva et al. (2002), somente no ano de 1999, em Uberlândia, foram solicitados 808 pedidos de cortes de árvores, que tinham como justificativa algum tipo de conflito com a rede elétrica, danos ao imóvel, danos nas calçadas e queda de folhas que causavam incômodos aos moradores.

Almeida e Barbosa (2010) descreveram que os moradores, ao plantar uma árvore na calçada, devem 


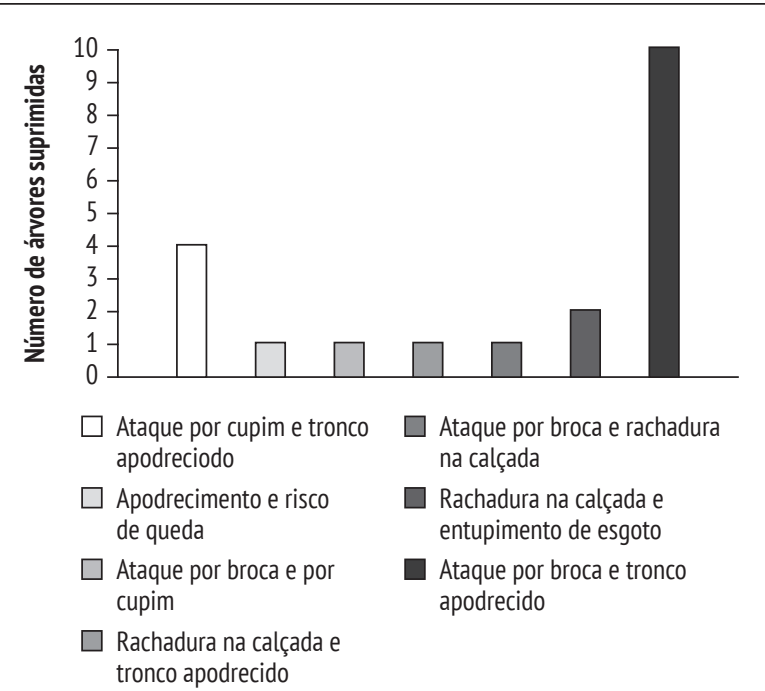

Figura 3 - Motivos associados de supressão de árvores no município de Itapira, SP, no período de janeiro a outubro de 2010

Fonte: Dados da pesquisa.

ser instruídos quanto às espécies mais indicadas e suas características inerentes, locais apropriados para adquirir as mudas, tutoramento, cuidados necessários pós-plantio e, principalmente, quanto à importância da arborização urbana das cidades.

Um dos problemas referentes à arborização de vias públicas sem a realização de um planejamento prévio é o plantio de espécies de grande porte em lugares inadequados. Esse procedimento é muito comum nas cidades brasileiras, causando, muitas vezes, sérios prejuízos como rompimento de fios de alta-tensão, interrupções no fornecimento de energia elétrica, entupimento de redes de esgoto, obstáculos para a circulação e acidentes envolvendo pedestres, veículos ou edificações (ALMEIDA; BARBOSA, 2010; FARIA et al., 2007), fatores esses que aumentam consideravelmente os pedidos de corte pelos munícipes.

Assim, na escolha das espécies para arborização urbana, devem ser avaliados alguns critérios, como o ritmo e exigências para o crescimento do vegetal, o tipo de copa, porte, folhagem, flores e frutos, problemas de toxidez, rusticidade, resistência e também a desrama natural. Outros parâmetros como largura da calçada, clima, solo e umidade da localidade também são variáveis que se mostram importantes na seleção das espécies para compor a arborização urbana (SILVA, 2005).

\section{Conclusões}

Com o mapeamento das supressões arbóreas por bairro, pode-se direcionar um planejamento adequado de reconstituição arbórea com o desenvolvimento de projetos de educação ambiental visando a uma maior conscientização da população para a importância da arborização urbana e a melhoria da qualidade de vida. Assim, é preciso planejar o plantio das árvores no perímetro urbano tomando como base os critérios técnicos adequados de forma a reduzir os danos materiais (danos a muros e calçadas) para que haja, de fato, uma redução do número de supressões arbóreas e que a população perceba os benefícios da arborização urbana, visando à melhoria do ambiente urbano tanto para a árvore quanto para a população.

\section{Referências}

ALVES, S. M.; GOUVEIA, V. V. Atitudes em relação à arborização urbana: uma contribuição da psicologia ambiental para a qualidade de vida urbana. Laboratório de Psicologia Ambiental, Brasília, v. 4, n. 6, 1995.

ALMEIDA, J. R. de; BARBOSA, C. G. Diagnóstico da arborização urbana da cidade de Cacoal (RO). Revista da Sociedade Brasileira de Arborização Urbana, v. 5, n. 1, p. 61-81, 2010.

BORTOLETO, S.; SILVA FILHO, D. F.; LIMA, A. M. L. P. Prioridades de manejo para a arborização viária da Estância de Águas de São Pedro (SP). Revista da Sociedade Brasileira de Arborização Urbana, v. 1, n. 1, p. 62-73, 2006.

COLETTO, E. P.; MÜLLER, N. G.; WOLSKI, S. S. Diagnóstico da arborização das vias públicas do município de Sete de Setembro (RS). Revista da Sociedade Brasileira de Arborização Urbana, v. 3, n. 2, p. 110-122, 2008.

FALEIRO, W.; AMÂNCIO-PEREIRA, F. Arborização viária do Campus Umuarama da Universidade Federal de Uberlândia - MG. Revista Científica Eletrônica de Engenharia Florestal, v. 6, n. 10, ago. 2007.

FARIA, J. L. G.; MONTEIRO, E. A.; FISCH, S. T. V. Arborização de vias públicas do município de Jacareí (SP). Revista da Sociedade Brasileira de Arborização Urbana, v. 2, n. 4, p. 20-33, 2007.

GRAZIANO, T. T. Viveiros municipais. Departamento de Horticultura - FCAVJ - UNESP. Notas de aula, 1994. 
GONÇALVES, S.; ROCHA, F. T. Caracterização da arborização urbana do Bairro de Vila Maria Baixa. ConSCIENTIAE SAÚDE, v. 2, p. 67-75, 2003.

INSTITUTO BRASILEIRO DE GEOGRAFIA E ESTATÍSTICA IBGE. Pesquisa Nacional de Saneamento Básico 2000. Rio de Janeiro: IBGE, 2002. Disponível em: <www.ibge. gov.br/home/estatistica/populacao/condicaodevida/ pnsb/pnsb.pdf>. Acesso em: 22 dez. 2009.

INSTITUTO DE PESQUISAS TECNOLÓGICAS - IPT. Instituto de Pesquisas Tecnológicas do Estado de São Paulo S.A. 2006. Disponível em: <http://www.ipt.br>. Acesso em: 7 jan. 2007.

ITAPIRA (Estado de São Paulo). Lei Complementar n. 3994, de 26 de outubro de 2006. Estabelece as diretrizes do planejamento territorial do município e toma outras providências. Itapira, 26 out. 2006.

MÜLLER, J. Orientação básica para manejo da arborização urbana. Porto Alegre: Nova Prova, 1998.

RIBEIRO, F. A. B. S. Arborização urbana em Uberlândia: percepção da população. Revista da Católica, Uberlândia, v. 1, n. 1, p. 224-237, 2009.

RODRIGUES, C. A. G. et al. Arborização urbana e produção de mudas de essências florestais nativas em Corumbá - MS. Corumbá: Embrapa Pantanal, 2002.

RODOLFO JUNIOR, F. et al. Análise da arborização urbana em bairros da cidade de Pombal no Estado da Paraíba. Revista da Sociedade Brasileira de Arborização Urbana, v. 3, n. 4, p. 3-19, 2008.

ROSSETTI, A. I. N.; PELLEGRINO, P. R. M.; TAVARES, A. R. As árvores e suas interfaces no ambiente urbano. Revista da Sociedade Brasileira de Arborização Urbana, v. 5, n. 1, p. 1-24, 2010.
SANTANA, J. R. F.; SANTOS, G. M. M. Arborização do campus da UEFS: exemplo a ser seguido ou um grande equívoco? Sitientibus, n. 20, p. 103-107, 1999.

SETZER, J. Atlas Climático do Estado de São Paulo. São Paulo: Secretaria da Agricultura, 1976.

SILVA, L. F. da. Situação da arborização viária de espécies para os bairros Antônio Zanaga I e II, da Cidade de Americana (SP). 2005. 80 f. Dissertação (Mestrado em Agronomia, área de concentração Fitotecnia) - Escola Superior de Agricultura "Luis de Queiroz", Universidade de São Paulo, Piracicaba, 2005.

SILVA FILHO, D. F.; PIZZETTA, P. U. C.; ALMEIDA, J. B. S. A. Banco de dados relacional para cadastro, avaliação e manejo da arborização em vias públicas. Revista Árvore, v. 26, n. 5, p. 629-642, 2002.

SILVA, E. M. da et al. Estudo da arborização urbana do bairro Mansour, na cidade de Uberlândia - MG. Caminhos de Geografia, v. 3, n. 5, p. 73-83, 2002.

TEIXEIRA, I. F. Análise qualitativa da arborização de ruas do Conjunto Habitacional Tancredo Neves, Santa Maria RS. Ciência Florestal, v. 9, n. 2, p. 9-21, 1999.

Recebido: 03/11/2010

Received: 11/03/2010

Aprovado: 09/09/2011

Approved: 09/09/2011 